April 30, 2021

2

3

4

\title{
Detecting natural selection in trait-trait coevolution
}

Daohan Jiang and Jianzhi Zhang*

Department of Ecology and Evolutionary Biology, University of Michigan, Ann Arbor, Michigan 48109, USA

\section{${ }^{*}$ Correspondence to}

Jianzhi Zhang

Department of Ecology and Evolutionary Biology

University of Michigan

4018 Biological Sciences Building

1105 North University Avenue

Ann Arbor, MI 48109, USA

Phone: 734-763-0527

Fax: 734-763-0544

Email: jianzhi@umich.edu

Running title: Selection in trait-trait coevolution

Keywords: fly, morphology, mutation, modularity, pleiotropy, yeast 


\section{ABSTRACT}

No phenotypic trait evolves independently of all other traits, but the cause of trait-trait

41 coevolution is poorly understood. While the coevolution could arise simply from pleiotropic

42 mutations that simultaneously affect the traits concerned, it could also result from multivariate

43 natural selection favoring certain trait relationships. To gain a general mechanistic

44 understanding of trait-trait coevolution, we examine the evolution of 220 cell morphology traits

45 across 16 natural strains of the yeast Saccharomyces cerevisiae and the evolution of 24 wing

46 morphology traits across 110 fly species of the family Drosophilidae, along with the variations of

47 these traits among gene deletion or mutation accumulation lines (a.k.a. mutants). For numerous

48 trait pairs, the phenotypic correlation among evolutionary lineages differs significantly from that

49 among mutants. Specifically, we find hundreds of cases where the evolutionary correlation

50 between traits is strengthened or reversed relative to the mutational correlation, which, according

51 to our population genetic simulation, is likely caused by multivariate selection. Furthermore, we

52 detect selection for enhanced modularity of the yeast traits analyzed. Together, these results

53 demonstrate that trait-trait coevolution is shaped by natural selection and suggest that the

54 pleiotropic structure of mutation is not optimal. Because the morphological traits analyzed here

55 are chosen largely because of their measurability, our conclusion is likely general. 


\section{INTRODUCTION}

Many phenotypic traits covary during evolution. For example, the logarithm of brain weight and that of body weight show a nearly perfect linear relationship across mammals (Gould, 1966; Huxley, 1972; Lande, 1979). In theory, three processes may explain such traittrait coevolution. First, it could arise simply from pleiotropic mutations that simultaneously influence these traits with a more or less constant ratio of effects (Lande, 1980; G. P. Wagner, 1989; G. P. Wagner \& Zhang, 2011). Second, trait covariation could arise from the linkage disequilibrium between genes controlling these traits (Gardner \& Latta, 2007; Lande, 2007; Saltz, Hessel, \& Kelly, 2017; G. P. Wagner \& Zhang, 2011), but such trait covariation is expected to be restricted to closely related individuals due to the deterioration of linkage disequilibrium as a result of recombination. If the linkage disequilibrium is stably maintained due to, for example, chromosomal inversion, the involved linked genes can be regarded as a supergene with mutational pleiotropy (Saltz et al., 2017). For this reason, linkage disequilibrium is negligible except for trait covariation among closely related individuals. Third, trait covariation could be a result of natural selection for particular trait relationships that are advantageous (Bolstad et al., 2015; Lande, 1979; Roff, Mostowy, \& Fairbairn, 2002; Shoval et al., 2012; Sinervo \& Svensson, 2002; Svensson et al., 2021).

Despite a long-standing interest in trait correlation in evolution (Lande, 1979; Saltz et al., 2017; G. P. Wagner \& Altenberg, 1996), which is also referred to as phenotypic integration in the literature (Olson \& Miller, 1999; Pigliucci, 2003), our understanding of the roles of mutation and selection in trait-trait coevolution remains limited. Most studies on the subject focused on a small number of traits that are physiologically or ecologically important (Kingsolver et al., 2001), such as skull anatomy characters (Fabre et al., 2020; Goswami, Smaers, Soligo, \& Polly,

80 2014; Navalon, Marugan-Lobon, Bright, Cooney, \& Rayfield, 2020; Porto et al., 2015; Simon,

81 Machado, \& Marroig, 2016; Watanabe et al., 2019), behavioral syndrome (i.e., sets of correlated

82 behavioral traits) (Dochtermann \& Dingemanse, 2013; Sih, Bell, \& Johnson, 2004), and

83 ecological or organismal traits correlated with the metabolic rate (Brown, Gillooly, Allen,

84 Savage, \& West, 2004; Glazier, 2010; Martin, 1981; Pettersen, White, \& Marshall, 2016; White

85 et al., 2019); hence, they may not provide a general, unbiased picture of trait-trait coevolution.

86 Additionally, it is the trait correlation resulting from standing genetic variation and its effect on

87 adaptation that have received the most attention (Agrawal \& Stinchcombe, 2009; Arnold, 
Burger, Hohenlohe, Ajie, \& Jones, 2008; Blows \& Mcguigan, 2015; Schluter, 1996; Steppan, Phillips, \& Houle, 2002; Walsh \& Blows, 2009; Walter, Aguirre, Blows, \& Ortiz-Barrientos, 2018). But, because standing genetic variation could have been influenced by selection, the resulting trait correlation may not inform the correlation produced by mutation. Not knowing the mutational correlation hinders a full understanding of the contribution of selection. that it is beneficial for organisms to have a modular organization such that functionally related traits belonging to the same module covary (Goswami et al., 2014; G. P. Wagner, 1999; G. P. Wagner \& Altenberg, 1996; G. P. Wagner, Pavlicev, \& Cheverud, 2007). Although modularity is a well-recognized feature of many trait correlation networks, the relative contribution of selection and mutational pleiotropy to modularity has not been assessed at the phenome scale (G. P. Wagner et al., 2007; Wang, Liao, \& Zhang, 2010).

To gain a general mechanistic understanding of trait-trait coevolution, we study the phenotypic correlations for a large number of trait pairs at the levels of mutation and long-term evolution; natural selection is inferred when the evolutionary correlation between traits cannot be fully explained by the mutational correlation. Our primary data include 220 cell morphology

104 traits of the budding yeast Saccharomyces cerevisiae that have been measured in 4817 singlegene deletion lines (Ohya et al., 2005), 89 mutation accumulation (MA) lines (for a subset of 187 traits) (Geiler-Samerotte, Zhu, Goulet, Hall, \& Siegal, 2016), and 16 natural strains with clear

107 phylogenetic relationships (Ohya et al., 2005; Yvert et al., 2013). These traits were quantified 108 from fluorescent microscopic images of triple-stained cells and were originally chosen for study 109 because of their measurability regardless of potential roles in evolution and adaptation (Ohya et 110 al., 2005). Subsequent studies found that these traits are correlated with the yeast mitotic growth 111 rate to varying extents (Ho \& Zhang, 2014). Hence, these traits may be considered

112 representatives of phenotypic traits that have different contributions to fitness. Previous analyses

113 of these traits among natural strains unveiled signals of positive selection on individual traits

114 (Ho, Ohya, \& Zhang, 2017), but their potential coevolution has not been studied. While studying 115 these trait pairs can offer a general picture of trait-trait coevolution, we recognize that the 116 selection agent would be hard to identify should selection be detected because the biological 117 functions of these traits (other than correlations with the growth rate) are generally unknown (Ho 118 et al., 2017). To verify the generality of the findings from the yeast traits, we analyze another 
dataset that includes 12 landmark vein intersections on the fly wings that have been measured in 150 MA lines of Drosophila melanogaster (Houle \& Fierst, 2013) and 110 Drosophilid species

121 (Houle, Bolstad, van der Linde, \& Hansen, 2017). Because each intersection is described by two

122 coordinates, which are counted as two traits, there are 24 traits in this dataset. In both datasets,

123 we discover that the evolutionary correlation differs significantly from the mutational correlation

124 for numerous trait pairs, revealing a role of natural selection in trait-trait coevolution. We also

125 provide evidence for selection for enhanced modularity of the yeast traits.

\section{RESULTS}

\section{Evolutionary correlations differ from mutational correlations for many trait pairs}

To investigate if trait correlations in evolution can be fully accounted for by the correlations generated by mutation, we examined all pairs of the 220 yeast cell morphology traits

131 previously measured. For each pair of traits, we computed the mutational correlation CORM, 132 defined as Pearson's correlation coefficient across 4,817 gene deletion lines (upper triangle in

133 Fig. 1A, Data S1), and evolutionary correlation $C O R_{\mathrm{E}}$, defined as Pearson's correlation

134 coefficient across 16 natural strains (lower triangle in Fig. 1A, Data S1) with their phylogenetic

135 relationships (Fig. S1) taken into account (see Materials and Methods). Note that the original 136 data contained 37 natural strains (Yvert et al., 2013), of which 21 belong to the "mosaic" group

137 (Liti et al., 2009; Peter et al., 2018)—-their phylogenetic relationships with other S. cereviase

138 strains vary among genomic regions - so cannot be included in our analysis that requires

139 considering phylogenetic relationships (Mendes, Fuentes-Gonzalez, Schraiber, \& Hahn, 2018).

140 For each pair of traits, a neutral distribution of $C O R_{\mathrm{E}}$ was generated by simulating 1,000 times

141 the neutral evolution of the traits under a multivariate Brownian motion model with the observed

142 mutational (co)variance matrix $M$ used as the mutational input, because, under neutrality, the

143 expected evolutionary divergence along a dimension in the phenotypic space is proportional of

144 the mutational variance along that dimension (Hohenlohe \& Arnold, 2008; Lande, 1979; Lynch

$145 \&$ Hill, 1986). A significant difference from $C O R_{M}(P<0.05)$ was inferred when the observed

$146 C O R_{\mathrm{E}}$ falls in the left or right $2.5 \%$ tail of the null distribution of $C O R_{\mathrm{E}}$. Note that the above test

147 has two limitations. First, it assumes that $M$ is invariant among the natural strains examined such

148 that a significant difference between $C O R_{\mathrm{E}}$ and $C O R_{\mathrm{M}}$ is caused by selection in trait-trait

149 coevolution instead of $M$ evolution. Second, our test cannot detect strain-specific selection on 
trait correlation, because $C O R_{\mathrm{E}}$ captures only the common pattern of trait correlation across the natural strains examined. Before conducting the test, we confirmed that the sampling error of our estimated $M$ is negligible, likely because of the large number of mutants used in $M$ estimation (Table S1; see Materials and Methods).

We found that the frequency distribution of $C O R_{\mathrm{E}}$ across all trait pairs differs significantly from that of $C_{0} O R_{\mathrm{M}}$ (Fig. S2A), suggesting the action of selection. Of the 24,090 trait pairs examined, 1,215 pairs (or 5.04\%) showed a significantly different $C O R_{\mathrm{E}}$ when compared with its neutral expectation from $C O R \mathrm{M}$, at the false discovery rate (FDR) of 5\% (Table 1, Data S1), indicating that natural selection has shaped the coevolution of many trait pairs. To investigate whether the above result is biased because of the use of each trait in many trait pairs, we randomly arranged the 220 traits into 110 non-overlapping pairs and counted the number of pairs with $C O R_{\mathrm{E}}$ significantly different from $C O R_{\mathrm{M}}$. This was repeated 1,000 times to yield 1000 estimates of the proportion of trait pairs with significantly different $C O R_{\mathrm{E}}$ and $C O R_{\mathrm{M}}$. The middle $95 \%$ of these estimates ranged from $1.82 \%$ to $9.09 \%$, with the median estimate being $4.55 \%$. Hence, there is no indication that using overlapping trait pairs has biased the estimate of the fraction of trait pairs with significantly different $C O R_{\mathrm{E}}$ and $C O R_{\mathrm{M}}$.

We divided the 1,215 cases of significantly different $C O R_{\mathrm{E}}$ and $C O R \mathrm{M}$ into three categories. In the first category, the trait correlation generated by mutation is strengthened by natural selection during evolution. A total of 393 trait pairs are considered to belong to this "strengthened" category (Table 1) because they satisfy the following criteria: $C O R_{\mathrm{E}}$ and $C O R_{\mathrm{M}}$ have the same sign and $\left|C O R_{\mathrm{E}}\right|>\left|C O R_{\mathrm{M}}\right|$, or $C O R_{\mathrm{E}}$ and $C O R_{\mathrm{M}}$ have different signs but only $C O R_{\mathrm{E}}$ is significantly different from 0 (at the nominal $P$-value of 0.05 ) (Fig. 1B). In the second category, the trait correlation generated by mutation is weakened by natural selection during evolution. One hundred and forty-five trait pairs satisfying the following criteria are classified into this "weakened" category (Table 1): $C O R_{\mathrm{E}}$ and $C O R_{\mathrm{M}}$ have the same sign and $\left|C O R_{\mathrm{E}}\right|<$ $\left|C O R_{\mathrm{M}}\right|$, or $C O R_{\mathrm{E}}$ and $C O R_{\mathrm{M}}$ have different signs but only $C O R_{\mathrm{M}}$ is significantly different from 0 (Fig. 1C). In the last category, the trait correlation generated by mutation is reversed in sign by natural selection during evolution. Six hundred and seventy-seven trait pairs satisfying the following criteria are in this "reversed" category (Table 1): $C O R_{\mathrm{E}}$ and $C O R_{\mathrm{M}}$ have different signs and are both significantly different from 0 (Fig. 1D). 
To assess the robustness of the selection signals detected, we repeated the above analysis using $C O R_{\mathrm{M}}$ estimated from 89 mutation accumulation (MA) lines (Geiler-Samerotte et al., 2016) (Fig. S3A, Data S1). Again, the overall frequency distribution across all trait pairs differs

183 significantly between $C O R_{\mathrm{E}}$ and $C O R_{\mathrm{M}}($ Fig. S2B $)$. We found that 1,718 trait pairs exhibit a significantly different $C O R_{\mathrm{E}}$ from its neutral expectation (Table 1, Data S1), supporting a role of selection in the coevolution of many trait pairs. When comparing the analysis using $C O R_{\mathrm{M}}$ from gene deletion lines and that using $C O R \mathrm{M}$ from MA lines, we found 429 trait pairs to exhibit selection signals and fall into the same category in both analyses, including 85 pairs in the "strengthened" category, 18 pairs in the "weakened" category, and 326 pairs in the "reversed" category. All of these numbers substantially exceed the corresponding expected random overlaps (3.4, 0.1, and 54.9, respectively; $P<0.001$ based on 1000 random draws in each case),

191 suggesting the reliability of both analyses. Although mutations in MA lines are more natural 192 than those in gene deletion lines, the number of MA lines is much smaller than the number of 193 gene deletion lines and only 187 of the original 220 traits were measured in the MA lines. For

194 these reasons, we focused on the $C O R \mathrm{M}$ estimated from the gene deletion lines in subsequent 195 analyses.

To examine the generality of the above yeast-based findings, we analyzed the 24 wing morphology traits of Drosophilid flies. The $C O R_{\mathrm{M}}$ and $C O R_{\mathrm{E}}$ have been previously estimated

198 from 150 MA lines (Houle \& Fierst, 2013) and 110 Drosophilid fly species (Houle et al., 2017),

199 respectively (Fig. S3B, Data S1). The overall frequency distribution across all trait pairs differs 200 significantly between $C O R_{\mathrm{E}}$ and $C_{\mathrm{M}}(\mathbf{F i g}$. S2C). Of the 276 pairs of traits, 152 showed a

201 significantly different $C O R_{\mathrm{E}}$ from its neutral expectation generated by simulating neutral

202 evolution with the estimated $C O R_{\mathrm{M}}$ (Table 1, Data S1), suggesting widespread actions of 203 selection in the coevolution of fly wing morphology traits.

204 Together, these results demonstrate that, for many trait pairs, mutational and evolutionary 205 correlations between morphological traits are more different than expected under neutrality.

206 This observation suggests an important role of selection in shaping the strength and/or direction 207 of trait correlation in evolution. 
The strengthened, weakened, and reversed trait correlations in evolution may have resulted from different selection regimes. Below we consider various selection regimes that

212 could potentially explain these types of difference between CORM and CORE (Fig. 2). First,

213 when a specific allometric relationship between two traits is selectively favored, the population

214 mean trait values are expected to be concentrated near the fitness ridge or the optimal allometric

215 line, resulting in a strong evolutionary correlation between the traits (i.e., a high $\left|C_{E} O R_{E}\right|$ ) (Fig.

216 2A). Unless $C O R_{\mathrm{M}}$ is already similar to $C O R_{\mathrm{E}}$, we expect to see strengthened or reversed $C O R_{\mathrm{E}}$

217 depending on CORM. Second, if there is a single fitness peak for an optimal combination of trait

218 values and if there is sufficiently strong stabilizing selection on the optimal phenotype, the

219 population mean phenotype should be restricted within a small range of the optimal phenotype in

220 all directions in the phenotypic space regardless of the mutational variance. Consequently,

$221 \operatorname{COR}_{E}$ is expected to be close to 0 , which could account for a weakened evolutionary correlation

222 relative to the mutational correlation (Fig. 2B). Finally, if the fitness optimum varies across

223 lineages in a random fashion, the steady-state $C O R_{E}$ will be close to zero, potentially leading to

224 the weakening of the evolutionary correlation relative to the mutational correlation (Fig. 2C).

225 To verify these predictions, we simulated the evolution of two traits. Under each

226 parameter set, we simulated 50 independent replicate lineages and computed the correlation

227 coefficient, or $C O R_{\mathrm{E}}$, between the traits across the replicate lineages at the end of the simulated

228 evolution. This was repeated 200 times to obtain an empirical distribution of CORE. To evaluate

229 the difference between $C O R_{\mathrm{M}}$ and $C O R_{\mathrm{E}}$, we examined the location of $C O R_{\mathrm{M}}$ in the distribution

230 of $C O R \mathrm{E}$; a significant $(P<0.05)$ difference is inferred if $C O R_{\mathrm{M}}$ is in the left or right $2.5 \%$ tail of

231 the CORE distribution.

232 As expected, in the absence of selection, the distribution of $C O R_{\mathrm{E}}$ is centered around

$233 \operatorname{COR}_{\mathrm{M}}$ (first block in Table 2). When a specific allometric relationship is selectively favored, a

234 high $\left|C O R_{\mathrm{E}}\right|$ always emerges regardless of the $C O R_{\mathrm{M}}$ used, resulting in either strengthened or

235 reversed evolutionary correlations $(P<0.005$ for all parameter sets examined; the second to fifth

236 blocks in Table 2). By contrast, stabilizing selection of an optimal phenotype leads to weakened

237 correlation across replicate lineages when $\left|C O R_{M}\right|$ is not small (sixth block in Table 2). Finally,

238 when different lineages have different phenotypic optima that are randomly picked from the

239 standard bivariate normal distribution, weakened evolutionary correlations are generally

240 observed except when $C O R \mathrm{M}$ is close to zero (bottom block in Table 2). These results suggest 
that the strengthened and reversed evolutionary correlations of yeast and fly morphological traits are likely caused by selections of allometric relationships, while the weakened correlations are

243 likely caused by selections of individual traits either when there is a single optimal phenotype or

244 when the optimal phenotype randomly varies among lineages.

\section{Selection for enhanced modularity of yeast morphological traits}

While all of the above analyses focused on individual trait pairs, here we ask whether the overall trait correlation across divergent lineages is stronger or weaker than that created by mutation. As a measure of the overall level of trait correlation (i.e., overall integration), we calculated the variance of eigenvalues $\left(V_{\text {eigen }}\right)$ of the correlation matrix from divergent lineages and mutants, respectively. A greater $V_{\text {eigen }}$ corresponds to a stronger overall correlation between traits because the eigenvalues become less evenly distributed as the absolute values of the correlation coefficients become larger (Pavlicev, Cheverud, \& Wagner, 2009). However, the sample size (i.e., the number of strains) in the estimation of the correlation matrix also has an effect on $V_{\text {eigen; }}$ a matrix estimated from a smaller sample naturally tends to have fewer positive eigenvalues and greater $V_{\text {eigen. }}$ To control this factor, we used 1,000 control datasets generated by simulating neutral evolution to derive an empirical null distribution of $V_{\text {eigen }}$ and examined the location of the observed $V_{\text {eigen }}$ in this distribution (see Materials and Methods).

For the yeast traits, $V_{\text {eigen }}$ of the observed evolutionary correlation matrix exceeds that in $90.8 \%$ of simulated datasets $(P=0.184$ in a two-tailed test; Table 3$)$, meaning that the overall evolutionary correlation between traits is not significantly different from the overall mutational correlation. For the fly traits, $V_{\text {eigen }}$ of the evolutionary correlation matrix exceeds that in $99 \%$ of

263 simulated datasets $(P=0.02$ in a two-tailed test; Table 3), suggesting that the overall

264 evolutionary correlation between traits is stronger than the overall mutational correlation. We 265 also compared the overall integration between yeast and flies using $V_{\text {eigen }} /(n-1)$, where $n$ is the 266 number of traits examined. $V_{\text {eigen }} /(n-1)$ equals 0.204 and 0.268 for the yeast mutational and

267 evolutionary matrices, respectively, whereas the corresponding values in flies are 0.153 and

2680.190 , respectively. Hence, the overall integration is substantially lower in flies than in yeast for 269 both mutational and evolutionary matrices.

In addition to the overall level of trait correlation, we also asked whether the correlational 
272 with that among mutants. To this end, we used a covariance ratio $(C R)$ test (Adams, 2016) that

273 compares covariance within and between pre-defined modules (see Materials and Methods).

274 Specifically, we calculated $C R$ for the evolutionary covariance matrix and compared it to the $C R$

275 distribution based on 1,000 covariance matrices generated through simulations of neutral

276 evolution. We treated the three non-overlapping categories of the yeast traits - actin traits,

277 nucleus traits, and cell wall traits (Ohya et al., 2005) — as three modules (Data S1). We found

278 that the $C R$ of the evolutionary covariance matrix exceeded that of every control dataset $(P<$

279 0.001; Table 3), suggesting natural selection for increased modularity in evolution. Consistent

280 with this result is the observation that trait pairs with significantly strengthened $C O R_{\mathrm{E}}$ are

281 enriched within modules ( $P=0.036$, randomization test), and this enrichment is particularly

282 strong for the nucleus module $(P<0.001$, randomization test). We did not analyze the fly data

283 here because of the unknown modular structure of this relatively small set of traits that are all

284 about the wing shape.

\section{DISCUSSION}

By comparing the trait-trait correlation across mutants $\left(C O R_{\mathrm{M}}\right)$ with that across divergent lineages $\left(C O R_{\mathrm{E}}\right)$ for 24,090 pairs of yeast cell morphology traits and 276 pairs of fly wing morphology traits, we detected the action of natural selection in trait-trait coevolution. The

290 fraction of trait pairs showing evidence for selection is substantially higher in the fly $(55.07 \%)$

291 than yeast $(5.04 \%)$ data $\left(P<10^{-4}\right.$, chi-squared test). This is at least in part caused by a difference

292 in statistical power, because the number of strains/species used for estimating $C O R_{\mathrm{E}}$ is much 293 greater for the fly (110) than yeast (16) data. It is likely that a much higher fraction than $5 \%$ of

294 the yeast trait pairs are subject to selection in their coevolution. Furthermore, as mentioned, our 295 comparison between $C O R_{\mathrm{E}}$ and $C O R_{\mathrm{M}}$ intends to test selection on trait correlations common 296 among the evolutionary lineages considered. If different evolutionary lineages have different 297 trait correlations, the $C O R_{\mathrm{E}}$ estimated from all lineages may not be significantly different from 298 CORM even when selection occurs in some or all of the lineages. In other words, our test is 299 expected to underestimate the proportion of trait pairs subject to selection. In our test, a null 300 distribution of $C O R_{\mathrm{E}}$ under neutrality was generated by simulating a Brownian motion with the 301 observed $M$ matrix used as mutational input. Although it is theoretically possible for non-neutral 302 evolution to behave like a Brownian motion, this should not impact our test because it is 
extremely unlikely for the non-neutral Brownian motion to follow $M$. Even under this unlikely scenario, a significant difference between $C O R_{\mathrm{E}}$ and $C O R_{\mathrm{M}}$ still signals selection while an equality between $C O R_{\mathrm{E}}$ and $C O R_{\mathrm{M}}$ may not prove neutrality. In other words, the potential nonneutral Brownian motion at most renders our test more conservative.

We demonstrated by population genetic simulation that various selection regimes can explain differences between $C O R_{\mathrm{M}}$ and $C O R_{\mathrm{E}}$. In particular, strengthened or reversed $C O R_{\mathrm{E}}$ relative to $C O R_{\mathrm{M}}$ can occur when a specific allometric relationship is preferred, while weakened $C O R_{\mathrm{E}}$ can occur under directional or stabilizing selection of individual traits. A notable difference between the simulation results and empirical observations is that the simulations tend to end up with extreme values of $\left|C O R_{E}\right|$ (i.e., close to either 1 or 0 ) except in the case of neutrality, whereas the empirically observed $\left|C O R_{E}\right|$ is usually less extreme even when $C O R_{\mathrm{M}}$ and $C O R_{\mathrm{E}}$ are significantly different. This is due to the fact that the simulation results usually

315 represent steady-state correlations across lineages. That is, the mean phenotype of each lineage 316 is at or near the corresponding optimum (if any); consequently, $\left|C O R_{E}\right|$ is close to 1 when the 317 optimum is a line and close to 0 when the optimum is a single combination of two trait values.

318 However, the population mean phenotypes may not be close to their optima in some strains

319 because of recent changes of the optima or the sparsity of mutations toward the optima, the latter

320 of which is well known as a potential hindrance to adaptation (Agrawal \& Stinchcombe, 2009;

321 Blows \& Mcguigan, 2015; Hansen \& Houle, 2008; Schluter, 1996). Another possibility is the

322 existence of a wide range of preferred allometry such that there is no strong selection for extreme

$323\left|C O R_{E}\right|$. Finally, selection may not result in the preferred allometry between two traits because

324 of the constraints from unconsidered traits (Houle, Jones, Fortune, \& Sztepanacz, 2019).

325 While selection was detected for many trait pairs, a large fraction of trait pairs, especially

326 in the yeast data, do not show a significant difference between $C O R_{\mathrm{E}}$ and $C O R \mathrm{M}$. These trait

327 pairs may be divided into two groups. In the first group, $C O R_{\mathrm{E}}$ and $C O R_{\mathrm{M}}$ are actually different,

328 but the difference is not found significant due to the limited statistical power. As mentioned, we

329 believe that a substantial fraction of yeast trait pairs fit this category due to the relatively low

330 statistical power for detecting the difference between $C O R_{\mathrm{E}}$ and $C O R_{\mathrm{M}}$ in the yeast data. In the

331 second group, $C O R_{\mathrm{E}}$ truly equals $C O R_{\mathrm{M}}$, which could result from one of the following three

332 scenarios. First, the specific trait-trait correlation does not impact fitness so evolves neutrally.

333 Second, the two traits have an intrinsic, immutable relationship (such as the hypothetical traits of 
334 body size and twice the body size), so will yield equal $C O R_{\mathrm{E}}$ and $C O R_{\mathrm{M}}$; this possibility can be 335 tested by examining the correlation of the two traits across isogenic individuals that show non336 heritable phenotypic variations (Geiler-Samerotte et al., 2020). The last and perhaps the most 337 interesting scenario is that the trait-trait correlation impacts fitness and hence has driven the 338 optimization of $C O R \mathrm{M}$ via a second-order selection (Hansen \& Houle, 2008; Ho \& Zhang, 2014;

339 A. Wagner, 2005), such that the first-order selection of mutations that affect the two traits is no

340 longer needed. However, the relative frequencies of these three scenarios are unknown.

In addition to pairwise trait correlations, we tested hypotheses regarding the evolution of

343 modularity across natural strains than across mutants but did not find evidence for a change of

344 overall phenotypic integration in evolution. These results support the view of increasing 345 modularity during evolution (Clune, Mouret, \& Lipson, 2013; Goswami et al., 2014; G. P.

346 Wagner, 1999; G. P. Wagner \& Altenberg, 1996; G. P. Wagner et al., 2007) but also suggest that

347 modularity is enhanced by both strengthening trait-trait correlations within modules and

348 weakening trait-trait correlations across modules. As mentioned, we indeed observed an

349 enrichment of strengthened $C O R_{\mathrm{E}}$ relative to $C O R_{\mathrm{M}}$ within modules. However, no enrichment of

350 weakened $C O R_{\mathrm{E}}$ between modules was detected, which may be because $\left|C O R_{\mathrm{M}}\right|$ between

351 modules is already quite small, making a further reduction in correlation relatively difficult to

352 detect statistically. In the fly data, we found evidence that natural selection has strengthened

353 overall morphological integration, contrasting the hypothesis of a reduced integration over time

354 (Goswami et al., 2014). One possible explanation is that the fly traits studied here are all

355 characters of the same organ (wing) and their evolution does not represent that of the whole

356 phenome but only one module. Another possibility is that the yeast cell morphology traits are

357 not comparable with the fly wing morphology traits if they belong to different levels of

358 biological organization (Zhang, 2018). However, for unicellular organisms like yeast, cellular

359 traits are also organismal traits, so there is no strong evidence that these two sets of traits are not

360 comparable. We did, however, found the overall integration lower for the fly than yeast traits,

361 but whether this observation indicates a lower integration for multicellular than unicellular

362 organisms requires analyzing more species and traits.

363 In this study, we compared $C O R_{\mathrm{M}}$ estimated from one yeast strain (BY) with $C O R_{\mathrm{E}}$

364 estimated from 16 different strains, under the assumption of a constant $C O R_{\mathrm{M}}$ across different 
strains. While it is a common practice to assume that the mutational architecture is more or less constant during evolution and to study phenotypic evolution by comparing mutational or genetic (co)variances in one species with those among different species (Ackermann \& Cheverud, 2004; Houle et al., 2017; Lynch, 1990), genetic variations affecting the genetic (co)variances of phenotypic traits have been reported (Jerison et al., 2017; Jones, Burger, \& Arnold, 2014; Pavlicev et al., 2008). As discussed earlier, such genetic variations may allow second-order selection of $C O R_{\mathrm{M}}$. For instance, it has been hypothesized that the optimization of mutational (co)variances driven by selection for mutational robustness and/or adaptability can lead to modularity (G. P. Wagner \& Altenberg, 1996; G. P. Wagner et al., 2007), but this process

374 presumably takes a much longer time than is relevant to the present study. Even without second375 order selection, $C O R \mathrm{M}$ may still vary across strains merely because the pleiotropic effects of a mutation may vary with the genetic background (Pavlicev \& Cheverud, 2015; Svensson et al., 2021). Regardless, in the future, it would be desirable to measure mutant phenotypes from multiple lineages to investigate whether $C O R_{\mathrm{M}}$ evolves, how rapidly it evolves, and whether its evolution is largely neutral or adaptive.

In summary, we detected the action of natural selection in shaping trait-trait coevolution. Because the traits analyzed here, especially the yeast traits, were chosen almost exclusively due to their measurability, our results likely reflect a general picture of trait-trait coevolution.

383 Measuring these yeast traits in additional divergent natural strains with clear phylogenetic 384 positions could improve the statistical power and clarify whether the fraction of trait pairs whose 385 coevolution is shaped by selection is much greater than detected here. Finally, the detection of selection for enhanced modularity of the yeast traits analyzed supports the hypothesis that modularity is beneficial (Goswami et al., 2014; G. P. Wagner \& Altenberg, 1996). The detection

388 of selection in trait-trait coevolution and selection for enhanced modularity suggests that the current pleiotropic structure of mutation is not optimal. This nonoptimality could be due to the

390 weakness of the second-order selection on mutational structure and/or a high dependence of the 391 optimal mutational structure on the environment, which presumably changes frequently. Future 392 studies on how the mutational structure evolves will likely further enlighten the mechanism of 393 trait-trait coevolution. 


\section{Phenotypic data}

The $S$. cerevisiae cell morphology traits were previously measured by analyzing fluorescent microscopic images. Three phenotypic datasets were compiled and analyzed in this study, including (i) 220 traits measured in 4718 gene deletion lines that each lack an nonessential gene (Ohya et al., 2005), (ii) the same 220 traits measured in 37 natural strains (Yvert et al., 2013), and (iii) 187 of the 220 traits measured in 89 mutation accumulation (MA) lines (Geiler-

402 Samerotte et al., 2016). When comparing patterns of trait correlation between two datasets, we 403 used traits available in both datasets.

Before the analyses, we first standardized all trait values by converting each trait value to

405 the natural $\log$ of the ratio of the original trait value to a reference. The standardized value of the

$406 i$ th trait in the $j$ th strain is $\tilde{X}_{i, j}=\ln \frac{X_{i, j}}{X_{i, r}}$, where $X_{i, j}$ is the original trait value and $X_{i, r}$ is the trait

407 value of the reference. For the gene deletion lines, the reference is the wild-type BY strain. For 408 the MA lines, the reference is the progenitor strain used in MA. For natural strains, the reference 409 is the same as the reference of the mutant strains to be compared with (i.e., wild-type BY or 410 progenitor of the MA lines).

411 The locations of 12 vein intersections on the fly wing were previously measured in 150

412 MA lines of Drosophila melanogaster and a mutational covariance matrix was estimated (Houle

$413 \&$ Fierst, 2013). These traits were also measured in 110 Drosophilid species and an evolutionary 414 covariance matrix was estimated with species phylogeny taken into account (Houle et al., 2017).

415 Both matrices are based on log-scale trait values.

\section{Influence of the sampling error on the $\boldsymbol{M}$ matrix}

418 To evaluate the influence of sampling error on the estimated $M$ matrix of yeast or fly, we 419 took samples (vectors of phenotypes) from the multivariate distribution of $M(4,817$ samples for 420 yeast gene deletion data and 150 samples for fly MA data), estimated a covariance matrix $(\widetilde{M})$

421 from these samples, and calculated Pearson's correlation coefficient between the eigenvalues of $422 M$ and $\tilde{M}$. This was repeated 1,000 times and the distribution of the correlation coefficient was 423 used to evaluate the potential impact of sampling error on $M$.

\section{Comparison of mutational and evolutionary correlations}


To take into account the phylogenetic relationships among yeast strains in estimating $C O R_{\mathrm{E}}$, we utilized a distance-based tree previously inferred (Peter et al., 2018) (Fig. S1). Strains with mosaic origins inferred in the same study (Peter et al., 2018) were removed before analysis, resulting in 16 remaining natural strains. Because the BY strain was not included in the data file in that study (Peter et al., 2018), W303, a laboratory strain closely related to BY, was chosen to represent BY. We obtained the evolutionary covariance matrix using the ratematrix function

432 from the R package geiger (Pennell et al., 2014; Revell, Harmon, Langerhans, \& Kolbe, 2007), 433 which calculates evolutionary covariances using the independent contrast method (Felsenstein,

434 1985). The evolutionary covariance matrix was then converted to the corresponding correlation 435 matrix.

To test whether there exists a significant modular structure among traits, we performed 437 the covariance ratio $(C R)$ test. For each pair of predefined modules, traits were first re-ordered 438 such that traits belonging to each module were located in the upper-left and lower-right corners of the covariance matrix, respectively, and $C R=\sqrt{\frac{\operatorname{trace}\left(M_{12} M_{21}\right)}{\sqrt{\operatorname{trace}\left(M_{11}^{*} M_{11}^{*}\right)+\operatorname{trace}\left(M_{22}^{*} M_{22}^{*}\right)}}}$, where $M_{12}$ and $M_{21}$ are the upper-right and lower-left sections of the original covariance matrix, respectively, containing all between-module covariances, $M_{11}^{*}$ is the upper-left section with diagonal elements replaced by zeros, $M_{22}^{*}$ is the lower-right section with diagonal elements replaced by zeros, and

$443 \operatorname{trace}(M)$ denotes the trace, or the sum of diagonal elements, of matrix $M$ (Adams, 2016).

444 Because three modules were defined in the yeast data, the average of all pairwise $C R$ values was 445 used to represent the overall modularity.

To test whether the observed pairwise trait correlations, overall phenotypic integration, or

447 modularity at the level of evolutionary divergence are significantly different from those expected

448 by mutation alone, we simulated neutral evolution along the phylogenetic tree that had been used

449 in estimating $C O R_{\mathrm{E}}$. A Brownian motion model was used to simulate phenotypic evolution such

450 that the amount of evolution in branch $i$ is $M_{i} l$, where $M_{i}$ is a vector sampled from the

451 multivariate normal distribution of the mutational covariance matrix $M$ and $l$ is the branch

452 length. Sampling was performed using the rmvnorm function in the R package mvtnorm (Genz, 453 2020). The starting value of each trait is 0 in all simulations. The phenotypic value of each

454 strain was obtained by adding up the amount of evolution on all branches ancestral to the strain.

455 This was repeated 1,000 times to obtain an empirical null distribution of CORE. The null 
456 distributions of $V_{\text {eigen }}$ and $C R$ were similarly obtained. In each two-tailed test, the $P$-value was

457 calculated by $P=\frac{2 \min \left(n_{H}, n_{L}\right)}{1000}$, where $n_{H}$ is the number of simulated values of the test statistic

458 that are higher than the observed value, $n_{L}$ is the number of those that are lower than the

459 observed value, and $\min \left(n_{H}, n_{L}\right)$ is the smaller of $n_{H}$ and $n_{L}$. The $P$-values for pairwise trait

460 correlations were converted to adjusted $P$-values following the Benjamini-Hochberg procedure

461 (Benjamini \& Hochberg, 1995) and an adjusted $P$-value below 0.05 indicates selection.

\section{Computer simulation of trait-trait coevolution under selection}

In each simulation, we considered a pair of traits with equal amounts of mutational variance $V_{\mathrm{M}}$, which is set to be 0.01 . The mutational covariance matrix is thus $M=$ $\left[\begin{array}{cc}V_{M} & C O V_{M} \\ C O V_{M} & V_{M}\end{array}\right]=\left[\begin{array}{cc}V_{M} & V_{M} C O R_{M} \\ V_{M} C O R_{M} & V_{M}\end{array}\right]$, where $C O V_{M}$ is the mutational covariance. The

467 number of mutations is a random Poisson variable with the mean equal to 1 . The phenotypic

468 effect of a mutation is drawn from the multivariate normal distribution of $M$ using the rmvnorm

469 function in the R package mvtnorm (Genz, 2020). The starting phenotype is $(0,0)$ in all

470 simulations.

We considered a Gaussian fitness function $f=\exp \left(-\frac{D^{2}}{2}\right)$, where $f$ is the fitness and $D$ is

472 the distance between the current phenotype and the optimal phenotype. When there is a single

473 fitness peak (i.e., the fitness optimum is a single point), $D$ is the Euclidean distance defined by

$\sqrt{d_{1}{ }^{2}+d_{2}{ }^{2}}$, where $d_{1}$ and $d_{2}$ are the distances between the current phenotypic values of the two

475 traits and their corresponding optima, respectively. When there is a fitness ridge (i.e., the fitness

476 optimum is a line), $D$ is the shortest distance from the current phenotype to the fitness ridge. The

477 selection coefficient $s$ equals $\frac{f}{f_{a}}-1$, where $f$ and $f_{a}$ are the fitness values of the mutant and wild-

478 type, respectively. The fixation probability of a newly arisen mutant is $P_{f}=\frac{1-\exp (-2 s)}{1-\exp \left(-2 N_{e} s\right)}$ in a

479 haploid population (Kimura, 1962), where the effective population size $N_{\mathrm{e}}$ was set at $10^{4}$. After

480 each unit time, the phenotypic effect of each mutation is added to the population mean at a

481 probability of $N_{e} P_{f}$; this probability is treated as 1 when $N_{e} P_{f}>1$ or when there is no selection.

482 Combinations of parameters used in the simulations are listed in Table 2. 
In simulations where different lineages are assigned different optima, each lineage's optimum was obtained by independently drawing the optimal values of the two traits from the standard normal distribution. Before conducting simulations, we confirmed that the optima of the two traits are not correlated (correlation coefficient $=0.0882, P=0.5423, t$-test).

All analyses in this study were conducted in R (R Core Development Team, 2010).

\section{ACKNOWLEDGEMENTS}

We thank members of the Zhang lab for valuable comments. This work was supported by U.S. National Institutes of Health grant R35GM139484 to J.Z.

\section{REFERENCES}

Ackermann, R. R., \& Cheverud, J. M. (2004). Detecting genetic drift versus selection in human evolution. Proc Natl Acad Sci US A, 101(52), 17946-17951. doi:10.1073/pnas.0405919102

Adams, D. C. (2016). Evaluating modularity in morphometric data: challenges with the RV coefficient and a new test measure. Methods in Ecology and Evolution, 7(5), 565-572. doi:10.1111/2041-210x.12511

Agrawal, A. F., \& Stinchcombe, J. R. (2009). How much do genetic covariances alter the rate of adaptation? Proceedings of the Royal Society B-Biological Sciences, 276(1659), 11831191. doi:10.1098/rspb.2008.1671

Arnold, S. J., Burger, R., Hohenlohe, P. A., Ajie, B. C., \& Jones, A. G. (2008). Understanding the Evolution and Stability of the G-Matrix. Evolution, 62(10), 2451-2461. doi:10.1111/j.1558-5646.2008.00472.X

Benjamini, Y., \& Hochberg, Y. (1995). Controlling the False Discovery Rate - a Practical and Powerful Approach to Multiple Testing. Journal of the Royal Statistical Society Series BStatistical Methodology, 57(1), 289-300. doi:DOI 10.1111/j.2517-6161.1995.tb02031.x

Blows, M. W., \& Mcguigan, K. (2015). The distribution of genetic variance across phenotypic space and the response to selection. Molecular Ecology, 24(9), 2056-2072. doi: $10.1111 / \mathrm{mec} .13023$

Bolstad, G. H., Cassara, J. A., Marquez, E., Hansen, T. F., van der Linde, K., Houle, D., \& Pelabon, C. (2015). Complex constraints on allometry revealed by artificial selection on the wing of Drosophila melanogaster. Proceedings of the National Academy of Sciences of the United States of America, 112(43), 13284-13289. doi:10.1073/pnas.1505357112

Brown, J. H., Gillooly, J. F., Allen, A. P., Savage, V. M., \& West, G. B. (2004). Toward a metabolic theory of ecology. Ecology, 85(7), 1771-1789. doi:Doi 10.1890/03-9000

Clune, J., Mouret, J. B., \& Lipson, H. (2013). The evolutionary origins of modularity. Proc Biol Sci, 280(1755), 20122863. doi:10.1098/rspb.2012.2863

Dochtermann, N. A., \& Dingemanse, N. J. (2013). Behavioral syndromes as evolutionary constraints. Behavioral Ecology, 24(4), 806-811. doi:10.1093/beheco/art002 
Fabre, A. C., Bardua, C., Bon, M., Clavel, J., Felice, R. N., Streicher, J. W., . . Goswami, A. (2020). Metamorphosis shapes cranial diversity and rate of evolution in salamanders. Nat Ecol Evol, 4(8), 1129-1140. doi:10.1038/s41559-020-1225-3

Felsenstein, J. (1985). Phylogenies and the Comparative Method. American Naturalist, 125(1), 1-15. doi:Doi 10.1086/284325

Gardner, K. M., \& Latta, R. G. (2007). Shared quantitative trait loci underlying the genetic correlation between continuous traits. Molecular Ecology, 16(20), 4195-4209. doi:10.1111/j.1365-294X.2007.03499.x

Geiler-Samerotte, K. A., Li, S., Lazaris, C., Taylor, A., Ziv, N., Ramjeawan, C., . . Siegal, M. L. (2020). Extent and context dependence of pleiotropy revealed by high-throughput single-cell phenotyping. Plos Biology, 18(8). doi:ARTN e3000836 10.1371/journal.pbio.3000836

Geiler-Samerotte, K. A., Zhu, Y. O., Goulet, B. E., Hall, D. W., \& Siegal, M. L. (2016). Selection Transforms the Landscape of Genetic Variation Interacting with Hsp90. Plos Biology, 14(10). doi:ARTN e2000465 10.1371/journal.pbio.2000465

Genz, A. B., F.; Miwa, T.; Mi, X.; Leisch, F.; Scheipl, F.; Hothorn, T. (2020). mvtnorm: Multivariate Normal and t Distributions. R package version 1.1-0, https:/CRAN.Rproject.org/package $=$ mvtnorm.

Glazier, D. S. (2010). A unifying explanation for diverse metabolic scaling in animals and plants. Biological Reviews, 85(1), 111-138. doi:10.1111/j.1469-185X.2009.00095.x

Goswami, A., Smaers, J. B., Soligo, C., \& Polly, P. D. (2014). The macroevolutionary consequences of phenotypic integration: from development to deep time. Philos Trans $R$ Soc Lond B Biol Sci, 369(1649), 20130254. doi:10.1098/rstb.2013.0254

Gould, S. J. (1966). Allometry and Size in Ontogeny and Phylogeny. Biological Reviews, 41(4), 587-640. doi:DOI 10.1111/j.1469-185X.1966.tb01624.X

Hansen, T. F., \& Houle, D. (2008). Measuring and comparing evolvability and constraint in multivariate characters. Journal of Evolutionary Biology, 21(5), 1201-1219. doi:10.1111/j.1420-9101.2008.01573.x

Ho, W. C., Ohya, Y., \& Zhang, J. Z. (2017). Testing the neutral hypothesis of phenotypic evolution. Proceedings of the National Academy of Sciences of the United States of America, 114(46), 12219-12224. doi:10.1073/pnas.1710351114

Ho, W. C., \& Zhang, J. (2014). The genotype-phenotype map of yeast complex traits: basic parameters and the role of natural selection. Mol Biol Evol, 31(6), 1568-1580. doi:Doi 10.1093/Molbev/Msu131

Hohenlohe, P. A., \& Arnold, S. J. (2008). MIPoD: a hypothesis-testing framework for microevolutionary inference from patterns of divergence. American Naturalist, 171(3), 366-385. doi:10.1086/527498

Houle, D., Bolstad, G. H., van der Linde, K., \& Hansen, T. F. (2017). Mutation predicts 40 million years of fly wing evolution. Nature, 548(7668), 447-450. doi:10.1038/nature23473

Houle, D., \& Fierst, J. (2013). Properties of Spontaneous Mutational Variance and Covariance for Wing Size and Shape in Drosophila Melanogaster. Evolution, 67(4), 1116-1130. doi:10.1111/j.1558-5646.2012.01838.x

Houle, D., Jones, L. T., Fortune, R., \& Sztepanacz, J. L. (2019). Why does allometry evolve so slowly? Integrative and Comparative Biology, 59(5), 1429-1440. doi:10.1093/icb/icz099

Huxley, J. (1972). Problems of relative growth. 2 d. 
Jerison, E. R., Kryazhimskiy, S., Mitchell, J. K., Bloom, J. S., Kruglyak, L., \& Desai, M. M. (2017). Genetic variation in adaptability and pleiotropy in budding yeast. Elife, 6 . doi:10.7554/eLife. 27167

Jones, A. G., Burger, R., \& Arnold, S. J. (2014). Epistasis and natural selection shape the mutational architecture of complex traits. Nature Communications, 5, 3709. doi:10.1038/ncomms4709

Kimura, M. (1962). On the probability of fixation of mutant genes in a population. Genetics, 47, 713-719.

Kingsolver, J. G., Hoekstra, H. E., Hoekstra, J. M., Berrigan, D., Vignieri, S. N., Hill, C. E., . . Beerli, P. (2001). The strength of phenotypic selection in natural populations. Am Nat, 157(3), 245-261. doi:10.1086/319193

Lande, R. (1979). Quantitative Genetic Analysis of Multivariate Evolution, Applied to Brain Body Size Allometry. Evolution, 33(1), 402-416. doi:DOI 10.1111/j.15585646.1979.tb04694.x

Lande, R. (1980). The Genetic Covariance between Characters Maintained by Pleiotropic Mutations. Genetics, 94(1), 203-215.

Lande, R. (2007). The maintenance of genetic variability by mutation in a polygenic character with linked loci (Reprinted). Genetics Research, 89(5-6), 373-387. doi:10.1017/S0016672308009555

Liti, G., Carter, D. M., Moses, A. M., Warringer, J., Parts, L., James, S. A., . . Louis, E. J. (2009). Population genomics of domestic and wild yeasts. Nature, 458(7236), 337-341.

Lynch, M. (1990). The Rate of Morphological Evolution in Mammals from the Standpoint of the Neutral Expectation. American Naturalist, 136(6), 727-741. doi:Doi 10.1086/285128

Lynch, M., \& Hill, W. G. (1986). Phenotypic evolution by neutral mutation. Evolution, 40(5), 915-935. doi:Doi 10.2307/2408753

Martin, R. D. (1981). Relative Brain Size and Basal Metabolic-Rate in Terrestrial Vertebrates. Nature, 293(5827), 57-60. doi:DOI 10.1038/293057a0

Mendes, F. K., Fuentes-Gonzalez, J. A., Schraiber, J. G., \& Hahn, M. W. (2018). A multispecies coalescent model for quantitative traits. Elife, 7. doi:10.7554/eLife.36482

Navalon, G., Marugan-Lobon, J., Bright, J. A., Cooney, C. R., \& Rayfield, E. J. (2020). The consequences of craniofacial integration for the adaptive radiations of Darwin's finches and Hawaiian honeycreepers. Nat Ecol Evol, 4(2), 270-278. doi:10.1038/s41559-0191092-y

Ohya, Y., Sese, J., Yukawa, M., Sano, F., Nakatani, Y., Saito, T. L., . . Morishita, S. (2005). High-dimensional and large-scale phenotyping of yeast mutants. Proceedings of the National Academy of Sciences of the United States of America, 102(52), 19015-19020. doi:10.1073/pnas.0509436102

Olson, E. C., \& Miller, R. L. (1999). Morphological integration (Pbk. ed.). Chicago: University of Chicago Press.

Pavlicev, M., \& Cheverud, J. M. (2015). Constraints Evolve: Context Dependency of Gene Effects Allows Evolution of Pleiotropy. Annual Review of Ecology, Evolution, and Systematics, Vol 46, 46, 413-434. doi:10.1146/annurev-ecolsys-120213-091721

Pavlicev, M., Cheverud, J. M., \& Wagner, G. P. (2009). Measuring Morphological Integration Using Eigenvalue Variance. Evolutionary Biology, 36(1), 157-170. doi:10.1007/s11692008-9042-7 
Pavlicev, M., Kenney-Hunt, J. P., Norgard, E. A., Roseman, C. C., Wolf, J. B., \& Cheverud, J. M. (2008). Genetic variation in pleiotropy: Differential epistasis as a source of variation in the allometric relationship between long bone lengths and body weight. Evolution, 62(1), 199-213. doi:10.1111/j.1558-5646.2007.00255.x

Pennell, M. W., Eastman, J. M., Slater, G. J., Brown, J. W., Uyeda, J. C., FitzJohn, R. G., . . Harmon, L. J. (2014). geiger v2.0: an expanded suite of methods for fitting macroevolutionary models to phylogenetic trees. Bioinformatics, 30(15), 2216-2218. doi:10.1093/bioinformatics/btu181

Peter, J., De Chiara, M., Friedrich, A., Yue, J. X., Pflieger, D., Bergstrom, A., . . Schacherer, J. (2018). Genome evolution across 1,011 Saccharomyces cerevisiae isolates. Nature, 556(7701), 339-344. doi:10.1038/s41586-018-0030-5

Pettersen, A. K., White, C. R., \& Marshall, D. J. (2016). Metabolic rate covaries with fitness and the pace of the life history in the field. Proceedings of the Royal Society B-Biological Sciences, 283(1831). doi:ARTN 20160323 10.1098/rspb.2016.0323

Pigliucci, M. (2003). Phenotypic integration: studying the ecology and evolution of complex phenotypes. Ecology Letters, 6(3), 265-272. doi:DOI 10.1046/j.1461-0248.2003.00428.x

Porto, A., Sebastiao, H., Pavan, S. E., VandeBerg, J. L., Marroig, G., \& Cheverud, J. M. (2015). Rate of evolutionary change in cranial morphology of the marsupial genus Monodelphis is constrained by the availability of additive genetic variation. $J$ Evol Biol, 28(4), 973985. doi:10.1111/jeb.12628

R Core Development Team. (2010). R: A language and environment for statistical computing.

Revell, L. J., Harmon, L. J., Langerhans, R. B., \& Kolbe, J. J. (2007). A phylogenetic approach to determining the importance of constraint on phenotypic evolution in the neotropical lizard Anolis cristatellus. Evolutionary Ecology Research, 9(2), 261-282.

Roff, D. A., Mostowy, S., \& Fairbairn, D. J. (2002). The evolution of trade-offs: Testing predictions on response to selection and environmental variation. Evolution, 56(1), 84-95.

Saltz, J. B., Hessel, F. C., \& Kelly, M. W. (2017). Trait Correlations in the Genomics Era. Trends in Ecology \& Evolution, 32(4), 279-290. doi:10.1016/j.tree.2016.12.008

Schluter, D. (1996). Adaptive radiation along genetic lines of least resistance. Evolution, 50(5), 1766-1774. doi:DOI 10.1111/j.1558-5646.1996.tb03563.x

Shoval, O., Sheftel, H., Shinar, G., Hart, Y., Ramote, O., Mayo, A., . . . Alon, U. (2012). Evolutionary trade-offs, Pareto optimality, and the geometry of phenotype space. Science, 336(6085), 1157-1160. doi:10.1126/science.1217405

Sih, A., Bell, A., \& Johnson, J. C. (2004). Behavioral syndromes: an ecological and evolutionary overview. Trends in Ecology \& Evolution, 19(7), 372-378. doi:10.1016/j.tree.2004.04.009

Simon, M. N., Machado, F. A., \& Marroig, G. (2016). High evolutionary constraints limited adaptive responses to past climate changes in toad skulls. Proc Biol Sci, 283(1841). doi:10.1098/rspb.2016.1783

Sinervo, B., \& Svensson, E. (2002). Correlational selection and the evolution of genomic architecture. Heredity (Edinb), 89(5), 329-338. doi:10.1038/sj.hdy.6800148

Steppan, S. J., Phillips, P. C., \& Houle, D. (2002). Comparative quantitative genetics: evolution of the G matrix. Trends in Ecology \& Evolution, 17(7), 320-327. doi:Pii S01695347(02)02505-3 Doi 10.1016/S0169-5347(02)02505-3 
Svensson, E. I., Arnold, S. J., Burger, R., Csillery, K., Draghi, J., Henshaw, J. M., . . Runemark, A. (2021). Correlational selection in the age of genomics. Nat Ecol Evol. doi:10.1038/s41559-021-01413-3

Wagner, A. (2005). Robustness and evolvability in living systems. Princeton, NJ: Princeton University Press.

Wagner, G. P. (1989). Multivariate mutation-selection balance with constrained pleiotropic effects. Genetics, 122(1), 223-234.

Wagner, G. P. (1999). A research programme for testing the biological homology concept. Novartis Found Symp, 222, 125-134; discussion 134-140.

Wagner, G. P., \& Altenberg, L. (1996). Perspective: Complex Adaptations and the Evolution of Evolvability. Evolution, 50(3), 967-976. doi:10.1111/j.1558-5646.1996.tb02339.x

Wagner, G. P., Pavlicev, M., \& Cheverud, J. M. (2007). The road to modularity. Nature Reviews Genetics, 8(12), 921-931. doi:10.1038/nrg2267

Wagner, G. P., \& Zhang, J. Z. (2011). The pleiotropic structure of the genotype-phenotype map: the evolvability of complex organisms. Nature Reviews Genetics, 12(3), 204-213. doi:10.1038/nrg2949

Walsh, B., \& Blows, M. W. (2009). Abundant Genetic Variation plus Strong Selection = Multivariate Genetic Constraints: A Geometric View of Adaptation. Annual Review of Ecology Evolution and Systematics, 40, 41-59. doi:10.1146/annurev.ecolsys.110308.120232

Walter, G. M., Aguirre, J. D., Blows, M. W., \& Ortiz-Barrientos, D. (2018). Evolution of Genetic Variance during Adaptive Radiation. American Naturalist, 191(4), E108-E128. doi:10.1086/696123

Wang, Z., Liao, B. Y., \& Zhang, J. (2010). Genomic patterns of pleiotropy and the evolution of complexity. Proc Natl Acad Sci US A, 107(42), 18034-18039. doi:10.1073/pnas.1004666107

Watanabe, A., Fabre, A. C., Felice, R. N., Maisano, J. A., Muller, J., Herrel, A., \& Goswami, A. (2019). Ecomorphological diversification in squamates from conserved pattern of cranial integration. Proc Natl Acad Sci U S A, 116(29), 14688-14697. doi:10.1073/pnas.1820967116

White, C. R., Marshall, D. J., Alton, L. A., Arnold, P. A., Beaman, J. E., Bywater, C. L., .. . Ortiz-Barrientos, D. (2019). The origin and maintenance of metabolic allometry in animals. Nat Ecol Evol, 3(4), 598-603. doi:10.1038/s41559-019-0839-9

Yvert, G., Ohnuki, S., Nogami, S., Imanaga, Y., Fehrmann, S., Schacherer, J., \& Ohya, Y. (2013). Single-cell phenomics reveals intra-species variation of phenotypic noise in yeast. BMC Syst Biol, 7, 54. doi:10.1186/1752-0509-7-54

Zhang, J. Z. (2018). Neutral Theory and Phenotypic Evolution. Molecular Biology and Evolution, 35(6), 1327-1331. doi:10.1093/molbev/msy065 
bioRxiv preprint doi: https://doi.org/10.1101/2021.05.05.442737; this version posted May 5, 2021. The copyright holder for this preprint (which was not certified by peer review) is the author/funder, who has granted bioRxiv a license to display the preprint in perpetuity. It is made available under aCC-BY 4.0 International license.

698 Table 1. Number of trait pairs with significantly different $C O R_{\mathrm{E}}$ and $C O R_{\mathrm{M}}$.

\begin{tabular}{llll} 
& \multicolumn{2}{c}{ Yeast } & Fly \\
\cline { 2 - 3 } & $\begin{array}{l}C O R_{\mathrm{M}} \text { from gene deletion } \\
\text { lines }(24,090 \text { trait pairs) }\end{array}$ & $\begin{array}{l}C O R_{\mathrm{M}} \text { from MA lines } \\
(17,391 \text { trait pairs })\end{array}$ & \\
\hline Strengthened & 393 & 578 & 57 \\
Weakened & 145 & 281 & 59 \\
Reversed & 677 & 859 & 36 \\
Total & 1215 & 1718 & 152 \\
\hline
\end{tabular}

699

700

701 
bioRxiv preprint doi: https://doi.org/10.1101/2021.05.05.442737; this version posted May 5, 2021. The copyright holder for this preprint (which

was not certified by peer review) is the author/funder, who has granted bioRxiv a license to display the preprint in perpetuity. It is made available under aCC-BY 4.0 International license.

702 Table 2. Parameters and results of simulations of trait-trait coevolution.

\begin{tabular}{|c|c|c|c|c|}
\hline Optimum & $C O R_{\mathrm{M}}$ & $\begin{array}{l}\text { Median } C O R_{\mathrm{E}} \text { at the end } \\
\text { of simulation }\end{array}$ & $\begin{array}{l}\text { Fraction of simulations with } \\
C O R_{\mathrm{E}}>C O R_{\mathrm{M}}\end{array}$ & $\begin{array}{l}C O R_{\mathrm{E}} \text { compared } \\
\text { with } C O R_{\mathrm{M}}\end{array}$ \\
\hline \multirow[t]{3}{*}{ No optimum } & 0.9 & 0.900 & $49.5 \%$ & No difference \\
\hline & 0.5 & 0.495 & $47.5 \%$ & No difference \\
\hline & 0.1 & 0.113 & $55.5 \%$ & No difference \\
\hline \multirow{3}{*}{$y=x^{*}$} & 0.9 & 1.000 & $100 \%$ & Strengthened \\
\hline & 0.5 & 1.000 & $100 \%$ & Strengthened \\
\hline & 0.1 & 1.000 & $100 \%$ & Strengthened \\
\hline \multirow[t]{3}{*}{$y=0.5 x$} & 0.9 & 1.000 & $100 \%$ & Strengthened \\
\hline & 0.5 & 1.000 & $100 \%$ & Strengthened \\
\hline & 0.1 & 1.000 & $100 \%$ & Strengthened \\
\hline \multirow[t]{3}{*}{$y=-0.5 x$} & 0.9 & -0.995 & $0 \%$ & Reversed \\
\hline & 0.5 & -0.999 & $0 \%$ & Reversed \\
\hline & 0.1 & -1.000 & $0 \%$ & Reversed \\
\hline \multirow[t]{3}{*}{$y=-x$} & 0.9 & -0.997 & $0 \%$ & Reversed \\
\hline & 0.5 & -0.999 & $0 \%$ & Reversed \\
\hline & 0.1 & -1.000 & $0 \%$ & Reversed \\
\hline \multirow[t]{3}{*}{$(0,0)$} & 0.9 & 0.0213 & $0 \%$ & Weakened \\
\hline & 0.5 & 0.00142 & $0.5 \%$ & Weakened \\
\hline & 0.1 & -0.0109 & $24 \%$ & No difference \\
\hline Drawn from & 0.9 & 0.0895 & $0 \%$ & Weakened \\
\hline \multirow[t]{2}{*}{$\mathcal{N}(\mathbf{0}, \mathbf{1})$} & 0.5 & 0.0874 & $0 \%$ & Weakened \\
\hline & 0.1 & 0.0866 & $6 \%$ & No difference \\
\hline
\end{tabular}

${ }^{*} x$ and $y$ respectively represent the values of the two traits considered. 
bioRxiv preprint doi: https://doi.org/10.1101/2021.05.05.442737; this version posted May 5, 2021. The copyright holder for this preprint (which was not certified by peer review) is the author/funder, who has granted bioRxiv a license to display the preprint in perpetuity. It is made available under aCC-BY 4.0 International license.

707 Table 3. Overall phenotypic integration $\left(V_{\text {eigen }}\right)$ and modularity $(C R)$ at the levels of mutation 708 and evolutionary divergence. Values at the level of mutation are medians from 1,000 control 709 sets.

\begin{tabular}{lllll}
\hline Statistic & Taxon & Mutation & Divergence & $P$-value \\
\hline$V_{\text {eigen }}$ & Yeast & 44.814 & 58.656 & 0.186 \\
& Fly & 3.530 & 4.359 & 0.02 \\
$C R$ & Yeast & 0.759 & 0.997 & $<0.001$ \\
\hline
\end{tabular}

710

711

712 

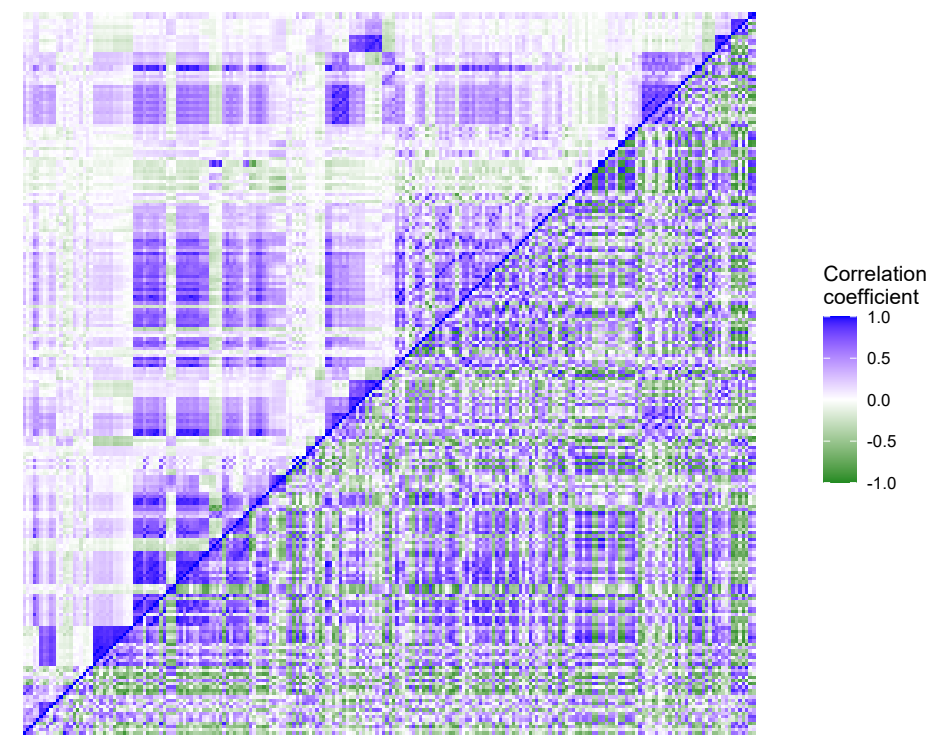

716

Trait 1

B

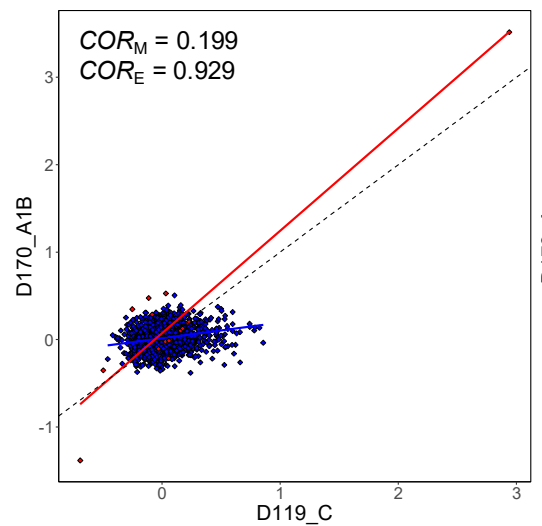

C

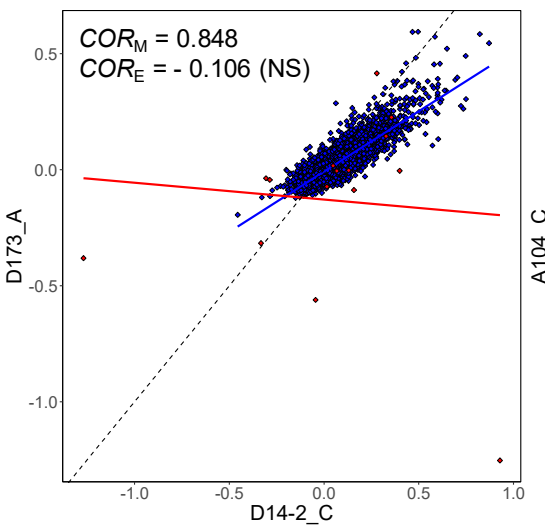

$\mathrm{D}$

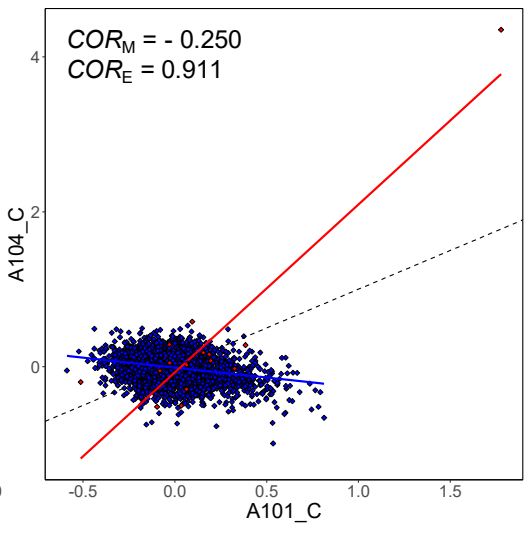

718

Figure 1. Detecting selection in yeast cell morphology trait-trait coevolution. (A) Mutational $\left(C O R_{\mathrm{M}}\right.$, upper triangle) and evolutionary $\left(C O R_{\mathrm{E}}\right.$, lower triangle) correlation matrices for the 220 yeast traits, which are ordered according to their IDs. (B) An example of evolutionarily strengthened correlation. (C) An example of evolutionarily weakened correlation. (D) An example of evolutionarily reversed correlation. In (B)-(D), each blue dot represents a gene deletion line (a.k.a. mutant) while each red dot represents an independent contrast derived from natural strains. Blue and red lines are linear regressions between the standardized values of the two traits in mutants and independent contrasts, respectively, while the dotted blackline shows the diagonal $(y=x)$. Trait IDs are shown along the axes. All $C O R_{\mathrm{M}}$ and $C O R_{\mathrm{E}}$ values shown are significantly different from 0 except when indicated by "NS" in the parentheses. 
$731 \quad \mathrm{~A}$

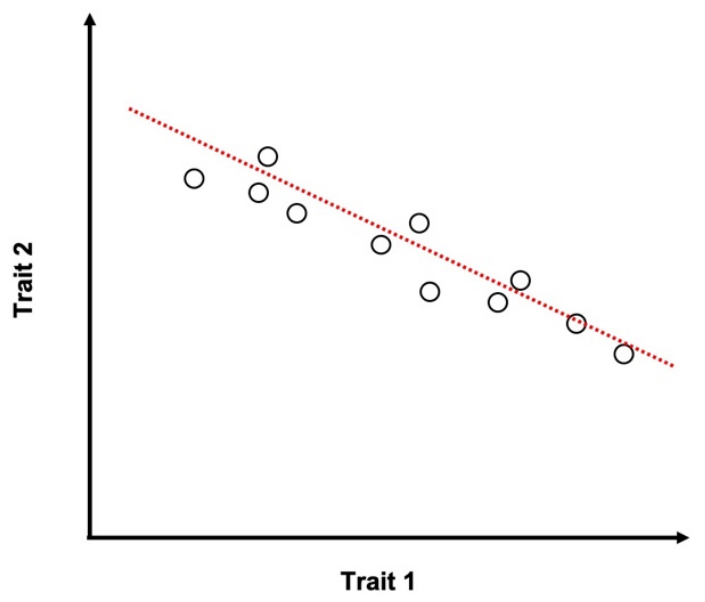

B

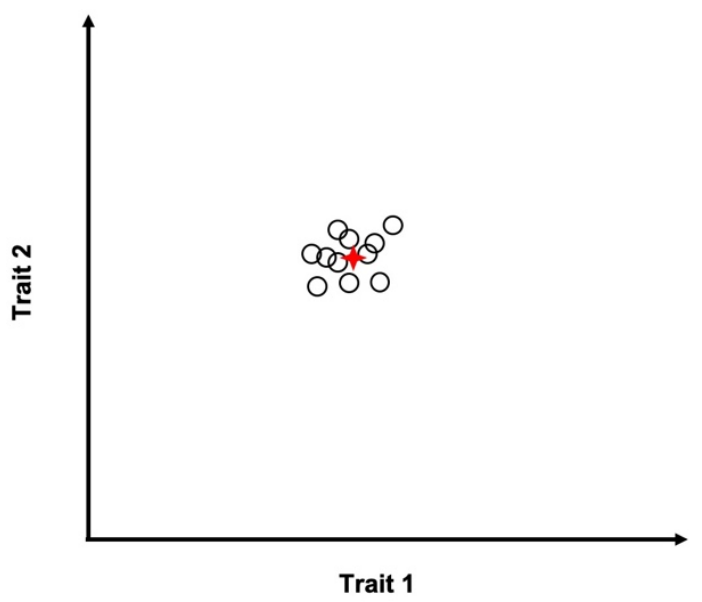

$735 \mathrm{C}$

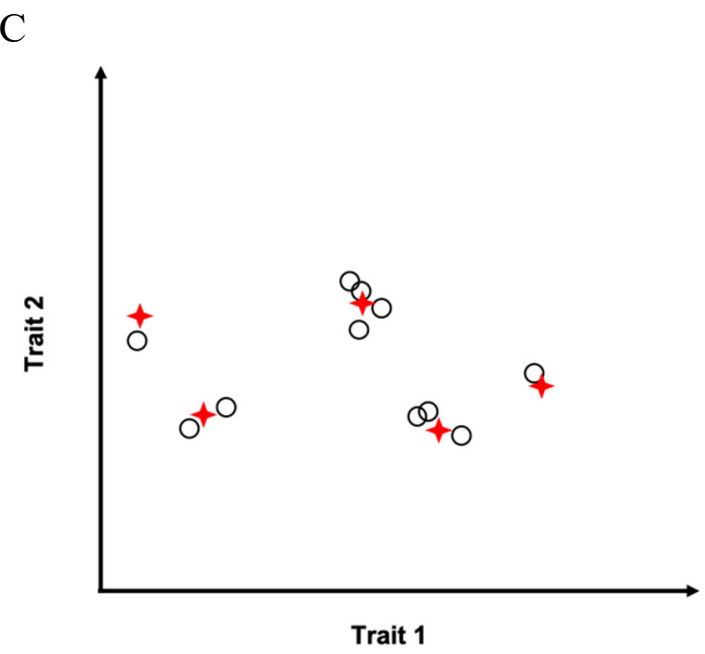

Figure 2. Schematic illustration of predictions made by models of trait-trait coevolution. Each circle represents the equilibrium mean phenotype of two hypothetical traits (trait 1 and trait 2) of a diverging lineage. (A) When a specific allometric relationship is selectively favored, the population mean phenotypes are distributed along the fitness ridge (i.e., the optimal allometric 
bioRxiv preprint doi: https://doi.org/10.1101/2021.05.05.442737; this version posted May 5, 2021. The copyright holder for this preprint (which

was not certified by peer review) is the author/funder, who has granted bioRxiv a license to display the preprint in perpetuity. It is made available under aCC-BY 4.0 International license.

741 line shown in red), resulting in a strong trait correlation across lineages. (B) When a specific 742 value is selectively favored for each trait, the population mean phenotypes are concentrated near 743 the optimal phenotype (marked by the red cross) and the trait correlation across lineages is weak. 744 (C) When different lineages have different optimal phenotypes (marked by red crosses) that are 745 randomly distributed, the trait correlation across lineages is weak. 
bioRxiv preprint doi: https://doi.org/10.1101/2021.05.05.442737; this version posted May 5, 2021. The copyright holder for this preprint (which was not certified by peer review) is the author/funder, who has granted bioRxiv a license to display the preprint in perpetuity. It is made available under aCC-BY 4.0 International license.

\section{Supplementary materials for "Detecting natural selection in trait-trait coevolution"}

D. Jiang \& J. Zhang

The supplementary materials include:

Table S1

Figures S1-S3

Data S1 (in a separate Excel file) 
bioRxiv preprint doi: https://doi.org/10.1101/2021.05.05.442737; this version posted May 5, 2021. The copyright holder for this preprint (which was not certified by peer review) is the author/funder, who has granted bioRxiv a license to display the preprint in perpetuity. It is made available under aCC-BY 4.0 International license.

Table S1. Pearson's correlation between eigenvalues of $M$ and those of the covariance matrix estimated from samples from $M(\widetilde{M})$. Results from 1000 replicates are shown.

\begin{tabular}{llll}
\hline Taxon & Sample size & Minimum correlation coefficient & Median correlation coefficient \\
\hline Yeast & 4,817 & 0.9993745 & 0.9999503 \\
Fly & 150 & 0.9698937 & 0.9967839 \\
\hline
\end{tabular}




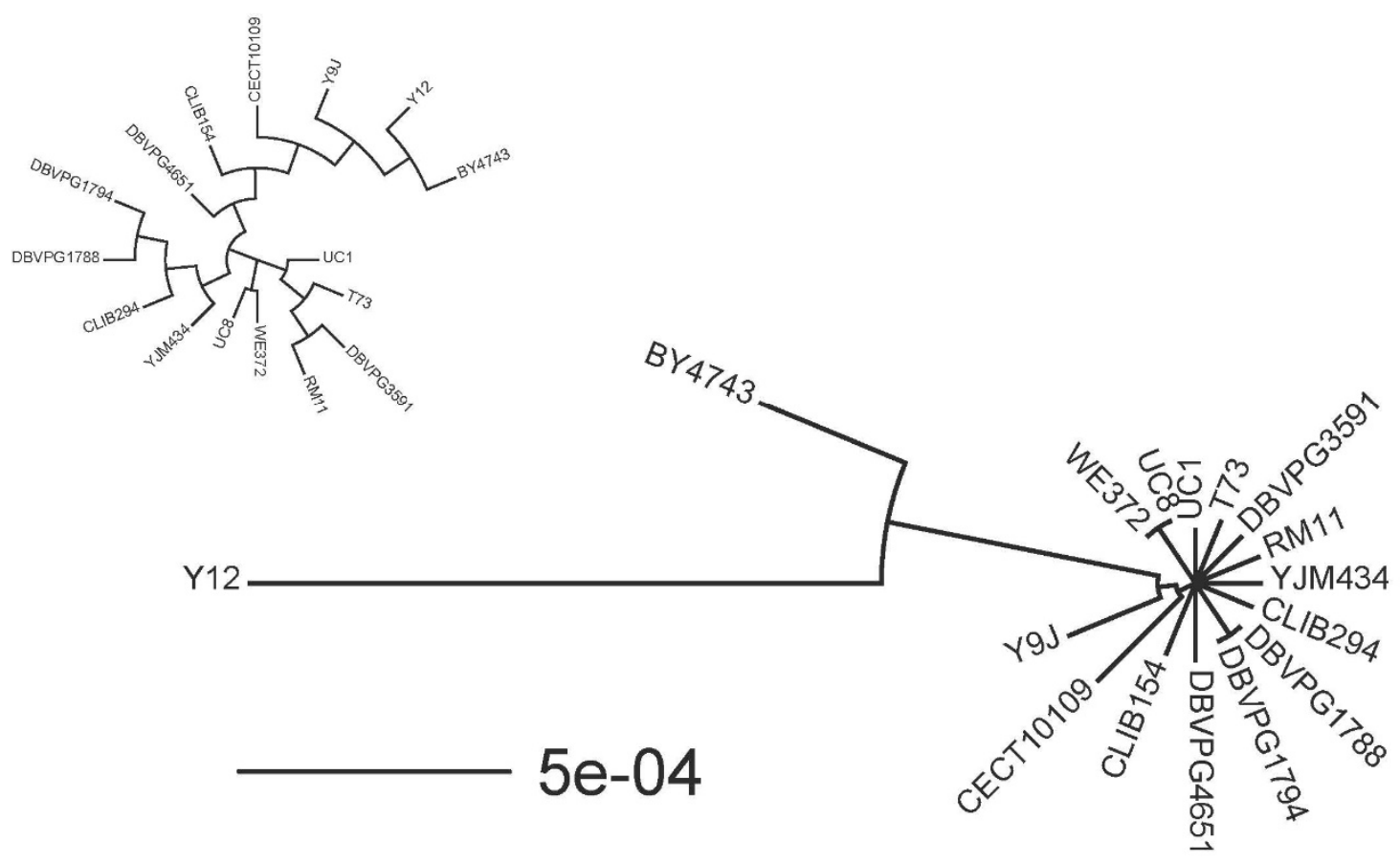

Fig. S1. Neighbor-joining tree of the 16 natural yeast strains used in this study, based on 1,544,489 biallelic single nucleotide polymorphism (SNP) sites. Scale bar indicates genomic divergence level. The tree was based on the distance matrix downloaded from

http://1002genomes.u-strasbg.fr/files/1011DistanceMatrixBasedOnSNPs.tab.gz. The inset at the top left coner shows the tree topology but the branch lengths are not drawn to scale. 
A

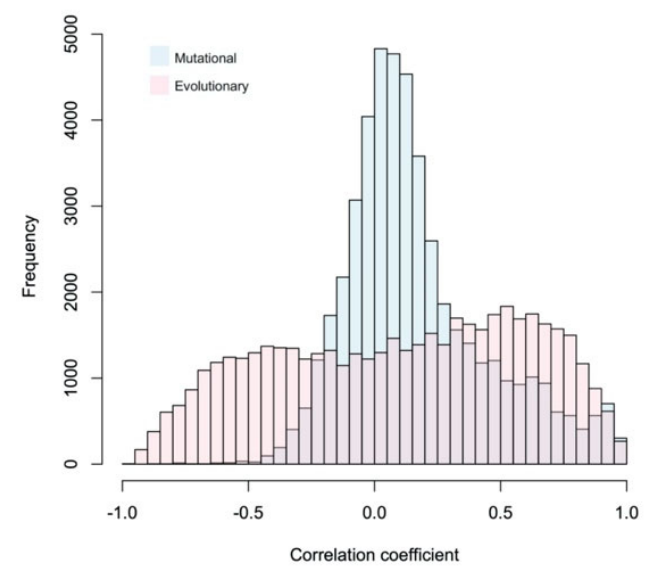

B

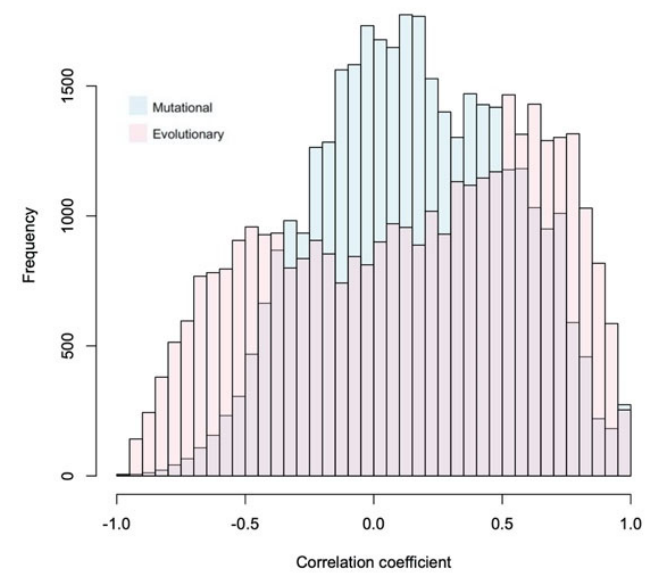

$\mathrm{C}$

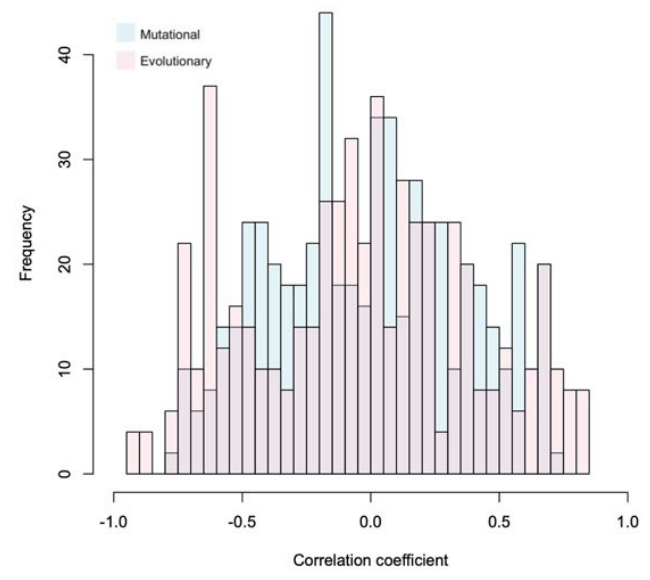

Fig. S2. Frequency distributions of multional $\left(C O R_{\mathrm{M}}\right)$ and evolutionary $\left(C O R_{\mathrm{E}}\right)$ correlations across all examined trait pairs. (A) Distributions for yeast when $C O R_{\mathrm{M}}$ is based on gene deletion 
bioRxiv preprint doi: https://doi.org/10.1101/2021.05.05.442737; this version posted May 5, 2021. The copyright holder for this preprint (which

was not certified by peer review) is the author/funder, who has granted bioRxiv a license to display the preprint in perpetuity. It is made available under aCC-BY 4.0 International license.

lines. (B) Distributions for yeast when $C O R_{\mathrm{M}}$ is based on MA lines. (C) Distributions for fly when $C O R_{\mathrm{M}}$ is based on MA lines. The distributions for $C O R_{\mathrm{M}}$ and $C O R_{\mathrm{E}}$ are significantly different in each panel $\left(P<10^{-10}\right.$ in $\mathrm{A}$ and $\mathrm{B}$ and $P=0.0015$ in $\mathrm{C}$, Kolmogorov-Smirnov test). 
bioRxiv preprint doi: https://doi.org/10.1101/2021.05.05 442737; this version posted May 5,2021 . The copyright holder for this preprint (which was not certified by peer review) is the author/funder, who has granted bioRxiv a license to display the preprint in perpetuity. It is made available under aCC-BY 4.0 International license.

A
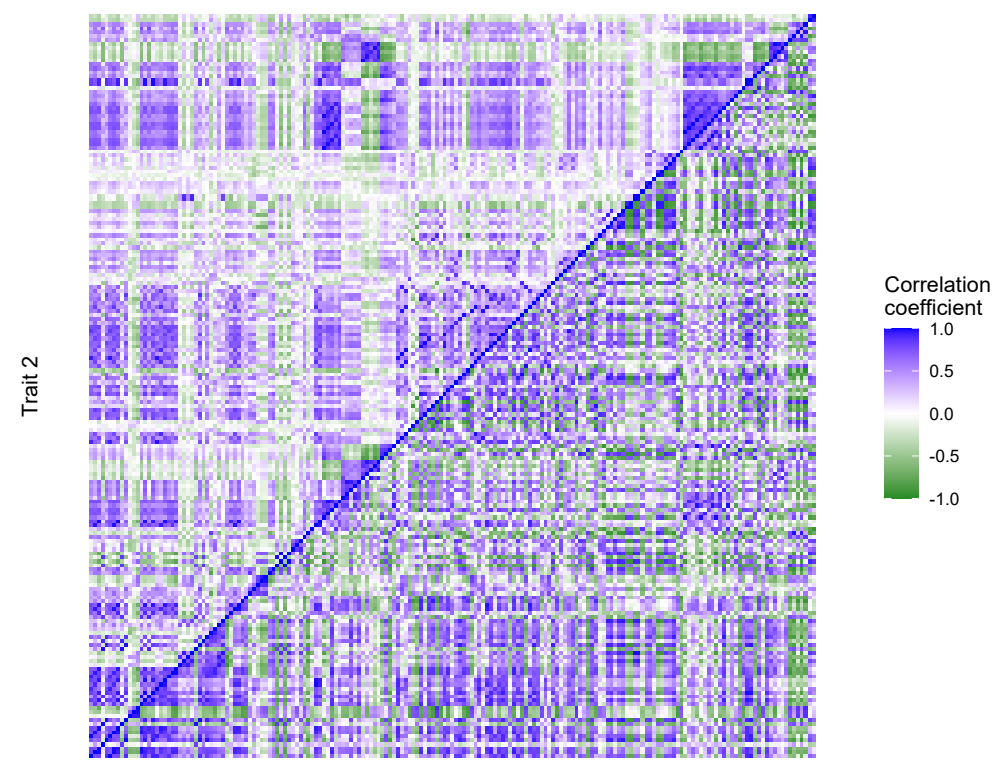

Trait 1

$\mathrm{B}$

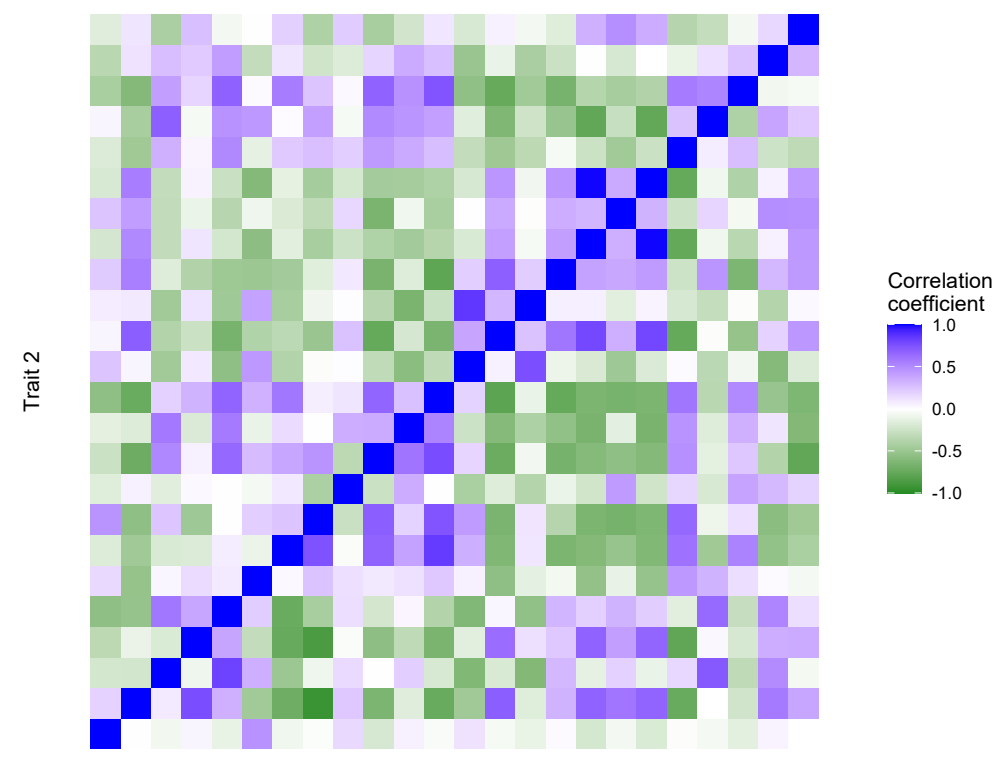

Trait 1

Fig. S3. Mutational (upper triangle) and evolutionary (lower triangle) correlation matrices for (A) the 187 yeast traits measured in MA lines, which are ordered according to their IDs, and (B) the 24 fly traits, which are ordered in the same way as in the original dataset. 